\title{
The Appearance of Trigeminal Ectopic Ganglia within the Surface Ectoderm in the Chick Embryo
}

\author{
Shigeru C. Kuratani and Shigeki Hirano \\ Department of Anatomy, Medical College of Georgia, Augusta, GA, U. S. A. \\ Received July 17, 1990
}

Summary. Aberrant ganglion cell morphogenesis associated with the ophthalmic placode was observed within the epidermis of the chick embryo at stages 20 through 26. This process was studied using immunohistochemistry and scanning and transmission electron microscopy. Clusters of ganglion cells were covered by epidermis and seen as epidermal nodules distributed diffusely in the supraorbital region. The ganglion cell clusters found within these nodules were not delineated by basement membrane from the epidermis, and were provisionally termed ectopic ganglia. The cell bodies within the ganglia possessed neurites containing microtubules and neurofilament protein. The cell bodies were also immunoreactive to monoclonal antibodies, E/C8 and HNK-1, indicating neuronal phenotypes. The neurites were often associated with the ophthalmic nerve or its branches as well as being distributed in the ectoderm. The ectopic ganglia seemed to represent the delayed gangliogenesis of a part of the ophthalmic placode which failed to detach from the ectoderm during ophthalmic ganglion formation.

In the development of cranial nerves, two sources of peripheral ganglia are observed: the neural crest and epibranchial placode. Recent experimental studies with various cell markers have revealed their contributions to the cranial sensory ganglia in avian embryos (reviewed by LE DOUARIN et al., 1984). Unlike other epibranchial placodes, the trigeminal placode is unusual in that it appears as a number of small local thickenings in the ectoderm, termed "area V" by BARTELMEZ and EvANS (1926). The morphological aspect of these placodal islets has not been extensively studied except for a few cases, e.g., BATTEN (1957) in the sheep embryo and CoERs (1946) in the rabbit.

In a previous study on the peripheral development of the trigeminal nerve, it was observed that the ophthalmic region of ectoderm seemed to undergo gangliogenesis while staying within the surface ectoderm (KURATANI and TANAKA, 1990). By applying immunohistochemical techniques to the wholemount specimen, the three-dimensional structure of this problematic ganglion was observed in relation to the surrounding structures. Neurites of these ganglia were often associated with the ophthalmic nerve anlage, and it was suggested that the ectopic ganglia shared the same origin as the ophthalmic ganglion (KURATANI and TANAKA, 1990). The present paper uses several histological techniques in describing the morphological features of this curious gangliogenesis of the surface ectoderm.

\section{MATERIALS AND METHODS}

Eggs of White Leghorn (whole-mount preparation) or Arbor Acre chickens (other preparations) were incubated in a hatching chamber at $37^{\circ} \mathrm{C}$ in a humid atmosphere. Embryonic stages were determined according to HAMBURGER and HAMILTON (1951). These two species showed no significant differences in the developmental stages or relevant structures examined.

\section{Immunohistochemistry}

Embryos were fixed for $1 \mathrm{~h}$ at room temperature in Bouin's fixative for HNK-1, in Carnoy's fixative for $\mathrm{E} / \mathrm{C} 8$, and in Zamboni's fixative for immunolocalization of the neurofilament protein (NFP). The embryos were embedded in paraffin and sectioned at $15 \mu \mathrm{m}$, deparaffinized, and treated with $2 \%$ periodic acid for $10 \mathrm{~min}$. The incubation with primary antibodies was 
as follows: for HNK-1, Leu-7 (Becton Dickinson, diluted $1 / 20$ ) was applied for $1 \mathrm{~h}$ at room temperature; E/C8 (gift of Gary Ciment, diluted 1/20) was applied for $1 \mathrm{~h}$ at room temperature; anti-NFP antibody (IT-0168, all neurofilaments, $70 \mathrm{~K}+160 \mathrm{~K}+210 \mathrm{~K}$, DP $5+43+12$, Cosmo Bio., diluted 1/100) was applied for 1 day at $4{ }^{\circ} \mathrm{C}$. All the primary antibodies were diluted in phosphate-buffered-saline (PBS) containing $0.3 \%$ Triton X-100, $0.2 \%$ BSA, $0.1 \%$ sodium azide. Secondary antibodies were diluted in PBS containing $0.3 \%$ Triton X-100, $0.2 \% \mathrm{BSA}$ and applied for $30 \mathrm{~min}$ for each primary antibody: For HNK-1, HRPconjugated anti-mouse IgM, diluted $1 / 400$, and for E/ $\mathrm{C} 8$ and anti-NFP antibody, HRP-conjugated antimouse IgG diluted $1 / 200$ was used. The peroxidase reaction was performed in $100 \mathrm{ml}$ Tris- $\mathrm{HCl}$ buffer containing $1.5 \mathrm{mg} 3,3$ '-diaminobenzidine and $10 \mu \mathrm{l}$ of $30 \%$ hydrogen peroxide.

\section{Whole-mount specimens}

Specimens were prepared by a method slightly modified from IsHIKAWA et al. (1986). Embryos were excised out of the eggs and fixed in Zamboni's fixative solution at $4^{\circ} \mathrm{C}$ for $4 \mathrm{~h}$, rinsed in PBS, treated with $1 \%$ periodic acid for $30-45 \mathrm{~min}$, rinsed in PBS, incubated for 1-2 overnight periods in freshly prepared $0.5 \%$ Triton $\mathrm{X}-100,0.5 \%$ saponin and $8 \%$ sucrose in PBS, and then frozen and thawed twice without washing. The embryos were incubated with the primary antibody diluted $1 / 100$ in PBS containing $0.2 \%$ bovine serum albumin (PBST-BSA), $0.3 \%$ Triton- $\mathrm{X}$ 100 and $0.1 \%$ sodium azide for $2-4$ days at $4{ }^{\circ} \mathrm{C}$. They were washed in PBS for $6 \mathrm{~h}$, and incubated in the secondary antibody - diluted $1 / 100$ in PBST-BSA without sodium azide - at $4{ }^{\circ} \mathrm{C}$ for 2 days. After the final washing in PBS7, the embryos were preincubated in the $40 \mathrm{ml}$ Tris- $\mathrm{HCl}$ buffer with $2 \mathrm{mg} 3$, 3'-diaminobenzidine (DAB) for $1 \mathrm{~h}$, and peroxidase reaction was performed at $0^{\circ} \mathrm{C}$. Specimens were transferred through a graded concentration series of glycerin/water and stored in $80 \%$ glycerin for observation.

\section{Preparation for scanning electron microscopy (SEM)}

The embryos were fixed in 5\% glutalaldehyde/PBS (pH 7.2), rinsed, and postfixed with $1 \%$ osmium tetraoxide/PBS. They were dehydrated in a graded concentration series of ethanol, critical point-dried, and sputter coated with gold palladium.

\section{Preparation for transmission electron microscopy (TEM)}

Specimens were fixed in $5 \%$ glutalaldehyde/PBS $(\mathrm{pH}$ 7.2), rinsed, and postfixed with $1 \%$ osmium tetraoxide/PBS. They were dehydrated and embedded in Epon-812 and sectioned.

\section{RESULTS}

\section{Immunohistochemical observations}

At stage 15 of the chick embryo, the ophthalmic nerve anlage connected with the supraorbital ectoderm by means of cellular bridges made of ectodermal cells (Fig. 1A, B). Such ectodermal cell connections were found along the length of the ophthalmic nerve representing the ophthalmic placode contributing to the nerve primordium. These placodal cells were not reactive to the HNK-1 which recognizes a carbohydrate epitope, one of the neuronal characteristics (Fig. 1A, B). By stage 17, the ophthalmic nerve primordium had moved medially and the placodal contribution had begun to cease (Fig. 1C). A few HNK-1-immunoreactive cells could be found within the ectoderm where the ophthalmic placode used to be located. They resembled neurons in their possession of neurite-like structures (Fig. 1C). Such structures were more frequently found in the stage 19 embryo (Fig. 1D).

Between stages 20 and 26 , a few ganglion-like structures were usually found associated with the

Fig. 1. Immunohistochemical sections of the developing ophthalmic nerve and ophthalmic placode. Every section has been stained with HNK-1. A. Stage 15 chick embryo. The amnion covers the embryo (left side). The distal portion of the ophthalmic nerve primordium is immunoreactive to the antibody $\left(V_{1}\right)$. This nerve primordium is united with the ectoderm of the supraorbital region by means of non-immunoreactive cell bridges (arrowheads), showing the placodal contribution to the ophthalmic ganglion. B. More proximal portion of the ophthalmic ganglion primordium $\left(V_{1}\right)$ of the same embryo as in A. The ganglion primordium is HNK-1immunoreactive, while the ectoderm and the bridges of placodal cells (arrowheads) are non-reactive. C. Stage 17 embryo. The distal portion of the ophthalmic nerve anlage is shown. Within the supraorbital ectoderm, an HNK-1-immunoreactive cell is seen (arrowhead). This cell seems to possess a neurite-like structure which is also immunoreactive. D. Stage 19 embryo. HNK-1-immunoreactive cells are found more frequently (arrowheads). A-D: $\times 125$ 


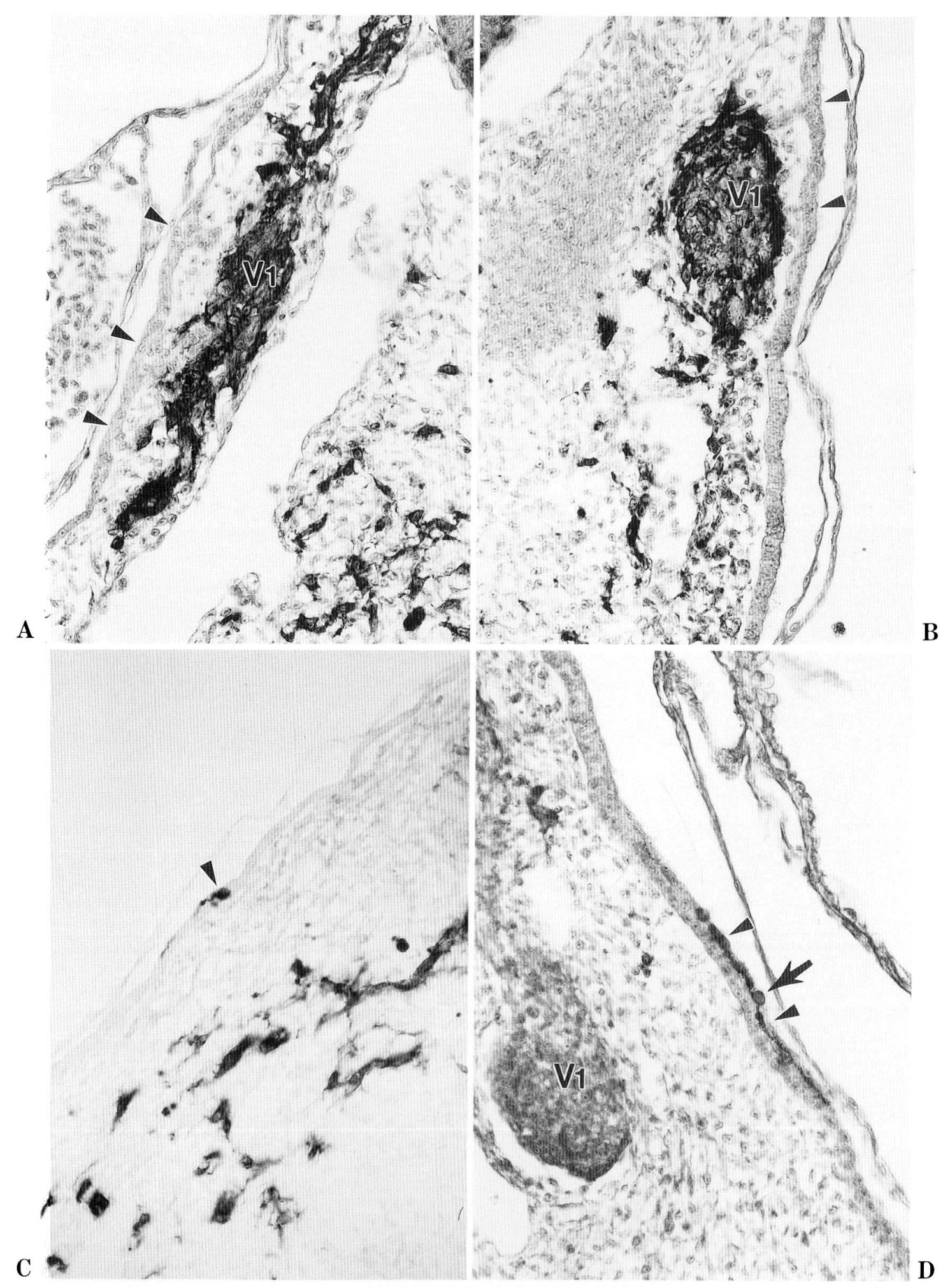

Fig. 1. Legend on the opposite page. 
A


B

C
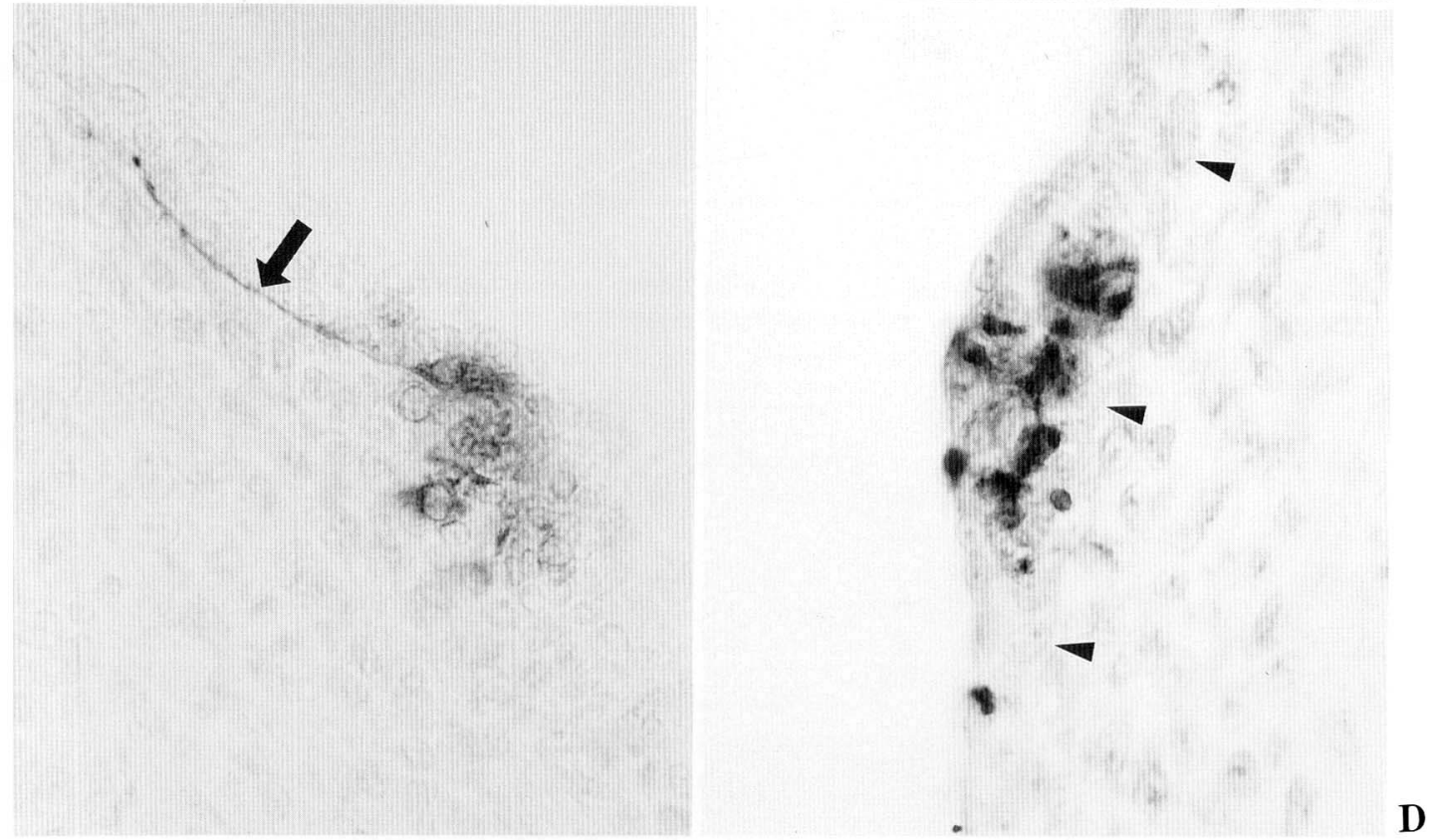

Fig. 2. Histology of ectopic ganglia. A. Nomarski microphotograph of the stage 23 ectopic ganglion. The specimen has been whole-mount-stained with anti-NFP antibody. The ganglion cell mass is seen in the box. The neurites from the ganglion can be fasciculated into a thick nerve bundle (solid arrow). Open arrows indicate the dorsal branches of the ophthalmic nerve. Note that some of the neurites with varicosities from the ectopic ganglion parallel the dorsal branches. $\times 320$. B. Higher magnification of the box in A. NFP-positive neurites are originating from the cell bodies of the ectopic ganglion. $\times 700$. C. The cells within the ectopic ganglion is reactive to $\mathrm{E} / \mathrm{C} 8$. A neurite-like structure is also immunoreactive (arrow). $\times 500$. D. Ectopic ganglion stained with HNK-1. The immunoreactive ganglion is located within the surface ectoderm and protrudes on the apical surface. The basal surface of the epidermis is indicated by arrowheads. Magnification same as C. $\times 500$ 



Fig. 3. Scanning electron micrograph of stage 25 embryo. A. Lateral view. On the surface ectoderm of the supraorbital area, nodules of ectodermal cells are seen (arrowheads). eb Eyeball, $m d$ mandibular process, $m x$ maxillar process. $\times 90$. B. Higher magnification of the left nodule in A. Note that the nodule is mainly covered by polygonal ectodermal cells and also a few round structures (apical dome or bleb) are seen protruding on the surface of the epidermal nodule. $\times 2,100$ 
A

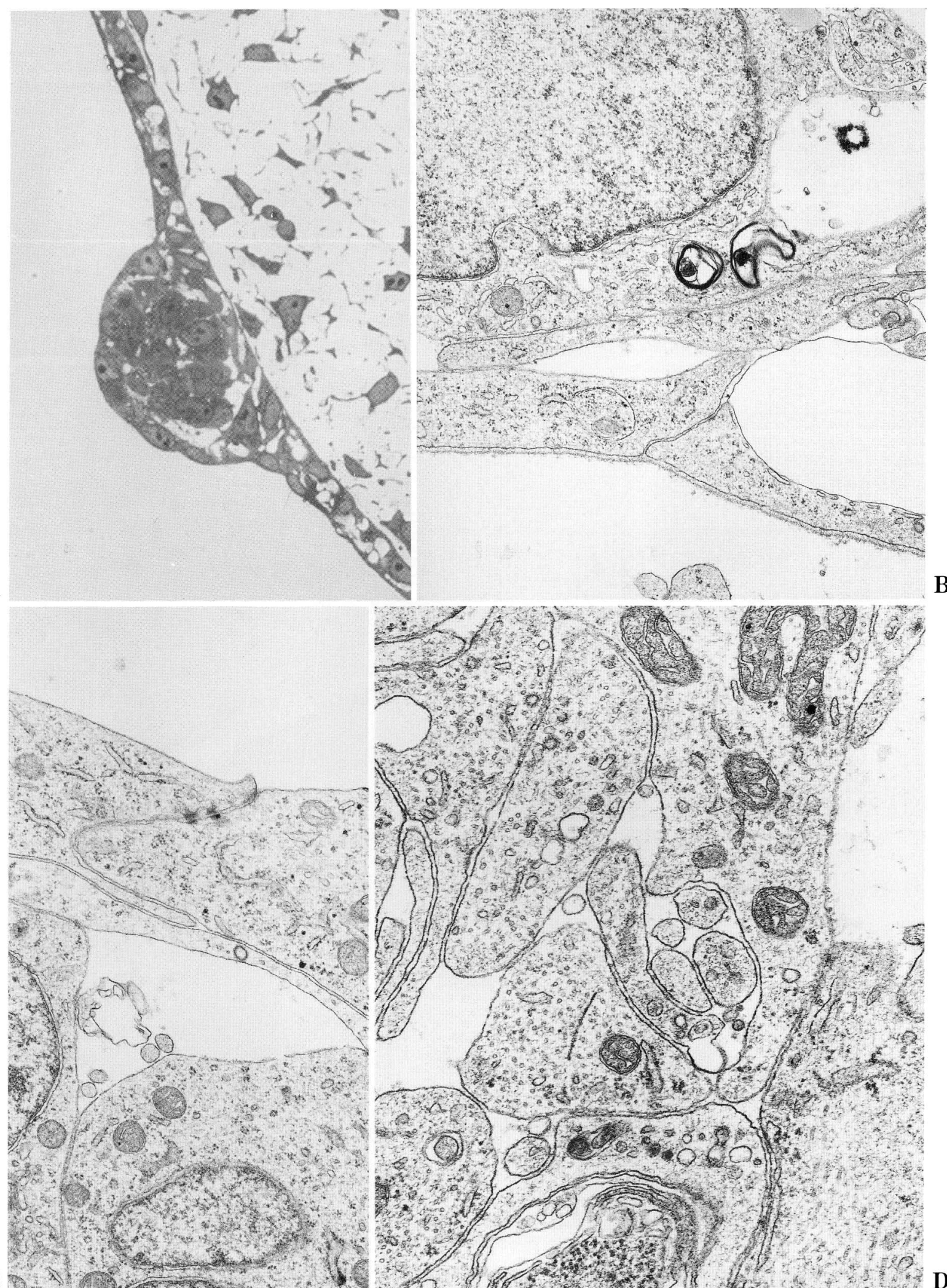

Fig. 4. Legend on the opposite page. 
epidermis of the supraorbital region which seemed to be correlated with the HNK-1-positive cells found in younger stages. In whole-mount specimens stained with anti-NFP antibody, these were located lateral to the mesenchyme-filled space formed through the mesencephalic flexure. NFP-positive neurites were seen passing from the ganglia in various directions; they sometimes fasciculated to form a thick bundle of nerve fibers at about stage 23 (Fig. 2A, B). Some of the bundles passed near the surface ectoderm, closely associated with the transient dorsal rami of the ophthalmic nerve (KURATANI and TANAKA, 1990, Fig. $2 \mathrm{~A}$ ), while others passed medially and connected directly with the ophthalmic nerve (Fig. 2). After stage 27 , no ectopic ganglia were observed.

In light of their neuron-like characteristics, these structures were interpreted as representing the ectopic ganglia. These ectopic ganglia were found protruding over the surface in most of the specimens (Fig. 2C, D). All of them showed NFP-like immunoreactivity around stage 22 . They often possessed neurite-like structures (Fig. 2C, E, see below). Inside the nodules, several cells were reactive both to monoclonal antibodies, HNK-1 and E/C8. E/C 8 has been known to react with the neurofilamentassociated protein (CIMENT et al., 1986). The neurites were also reactive to $\mathrm{E} / \mathrm{C} 8$ and anti-NFP antibodies (Fig. 2C, E).

\section{SEM observations}

When observed in the scanning electron microscope, the ectopic ganglia were seen as nodules protruding on the surface of the embryo (Fig. 3A). They were mainly covered by polygonal epithelial cells resembling normal epidermal cells (Fig. 3B). A few round shaped structures could be found on the surface whose nature was unknown (Fig. 3B). Similar structures have been reported in the trigeminal placode of early mouse embryos, and called apical domes or blebs by NicHOLs (1986). The structure of the nodules observed in the chick varied considerably. Many of them were seen as low protrusions, while some were large and constricted at the base, where they were
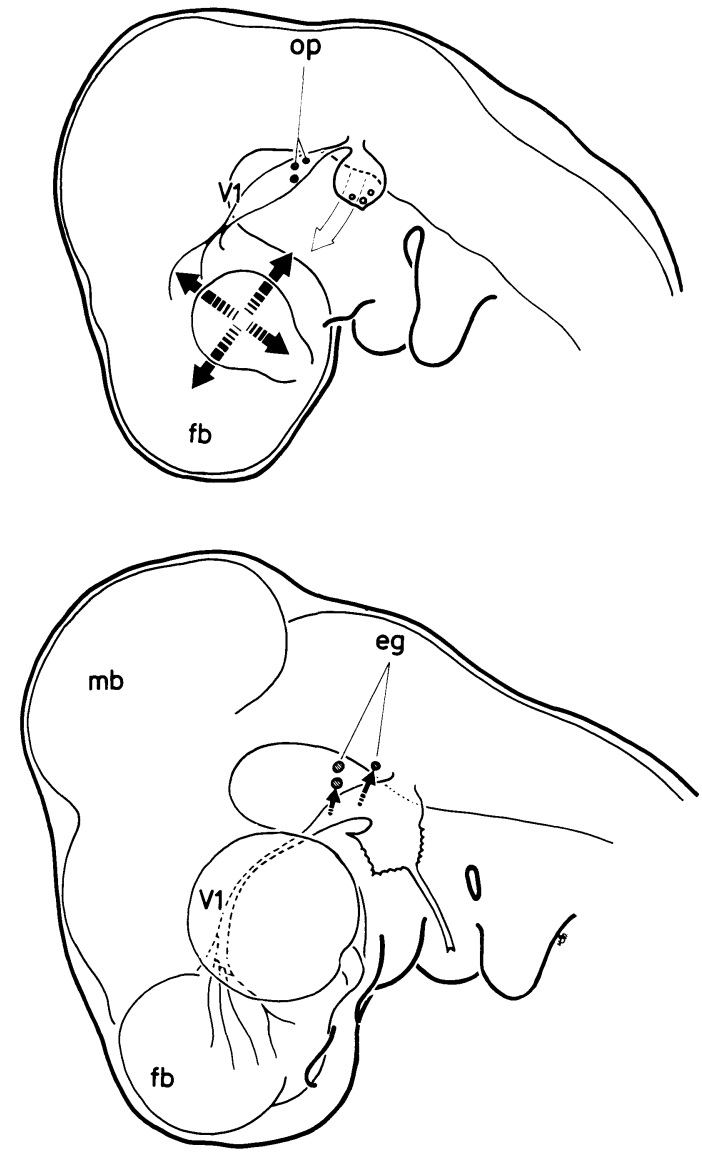

Fig. 5. A hypothetical development of ectopic ganglia. Top: Stage 17 chick embryo. Ophthalmic nerve anlage is located dorsal to the eye, near the ectoderm, and from the ophthalmic placodes $(o p)$. Open arrow indicates the future pontine flexure, and solid arrows the enlargement of the eyeball. Bottom: Stage 23 chick embryo. Ventromedial movement of the ophthalmic nerve is correlated with the rapid growth of the eyeball. Pontine flexure and enlargement of the eyeball result in the separation of the ophthalmic nerve and ectopic ganglia (small arrows).

Fig. 4A. Semi-thin section of epidermal nodule at stage 24 . Note that, within the nodule, there is a space between the inner cell mass and epidermal cells. $\times 440$. B-D. Transmission electron micrograph of the epidermal nodule. The same specimen as A. B. The basement membrane is opposed to the mesenchymal space. $\times 18,000$. C. The superficial cells appear as normal epidermal cells usually connected with each other by means of developing junctional complexes. $\times 18,000$. D. The inner cell mass. Among the cells, many neuritelike processes containing microtubules are observed. $\times 33,000$ 
attached to the surface ectoderm. Such larger nodules were more often encountered in older specimens before stage 27 .

\section{TEM observations}

When observed in semi-thin sections, the epidermal nodule of the stage 24 embryo had a space between the epidermal cells and inner cell mass within itself (Fig. 4A). However, no basement membrane was observed in this space between the ganglion-like cells and the epidermal cells, but rather under the nodule proper (Fig. 4B). As mentioned in the SEM description, the outer layer of this nodule was made of normal epidermal cells which were connected with each other by means of desmosomes (Fig. 4C), while the inner cells, not connected by developed junctions, possessed neurite-like processes which contained microtubules, making them neuron-like in appearance (Fig. 4D). The apical dome/bleb-like structures observed in SEM were not found in TEM observation probably because the specimen was not sectioned across the plane containing them.

\section{DISCUSSION}

The above has described the transient appearance of ganglion-like structures in the chick embryo. The overall appearance of this structure favors the idea that they represent masses of neurons located in the epidermis, i.e., they show NFP-, E/C8-, and HNK-1immunoreactivities, and possess neurite-like structures containing microtubules. As noted previously, these structures are in close association with the ophthalmic nerve (KURATANI and TANAKA, 1990). A number of studies have been made of the vertebrate cranial nerve ganglia. Among these, ophthalmic and maxillomandibular placodes are characterized by their diffuse localization (COGHILL, 1916; GOLDBY, 1928; COERS, 1946; HALley, 1955; BATTEN, 1957; D'Amico-Martel and Noden, 1983). HALley (1955) reported that the "area V" of BARTELMEZ and EvANS (1926), "... shows punctate prolifemative activity", and that "nodules and strands of epithelial cells may be seen in all stages of detachment from the undersurface of the ectoderm". HALLEY related them to the ophthalmic ramus of the trigeminal nerve. As has been described by JOHNSTON and HAZELTON (1972), such a diffused localization of the trigeminal placode might be related to the fact that the pharyngeal endoderm of this region is widely separated from the ectoderm. The role of the pharyngeal endoderm in focusing the gangliogenic cell population in the ectoderm has been suggested by YNTEMA (1944), NewTh (1956), and by Johnston and HazeltoN (1972).

In all the above literature, no ectopic ganglion has been reported except for one possible description which shows a striking resemblance to the ectopic ganglion in the chick. In amphibian larvae (Ambystoma), CoGHILL (1916) has reported structures similar to those observed in this study, being lateral to the ophthalmic ganglion primordium, and "just dorsal to the future lens". These were also epidermal nodules which were not connected with the ophthalmic nerve, and became distinctive at later stages. He also illustrated that "the ophthalmic ganglion was once adhered to the ectoderm at the very site where these thickenings appeared later on." Although he mentioned the similarity of this thickening to the lateral line system, he did not go further into this problem.

The in situ gangliogenesis of the "ophthalmic placode to be" ectoderm seems to hold true for the idea by D'AMICO-MARTEL (1982) that the placodederived ganglion cells undergo terminal mitosis when the cells are situated in the ectoderm. In the present study, these cells were not only reactive to the antiNFP antibody, but also possessed rather complete neuronal characteristics when observed in TEM. It has been reported that the placodal ganglion precursors have to penetrate the basement membrane to reach the trigeminal ganglion primordium in the mammalian embryo (NICHOLS, 1986). Thus, it seems most appropriate to assume that the ectopic ganglion corresponds to the ophthalmic placode which, for some reason, failed to be released from the ectoderm.

There are several embryological events which may be related to the ectopic ganglion formation, i.e., the pontine flexure, long-term gangliogenesis of the ophthalmic placode, and the enlargement of the eyeball. Most of these factors are unique to trigeminal nerve development and do not play a role in the development of more caudal cranial nerves. It seems possible to explain ectopic ganglion formation as an incidental gangliogenesis which is brought about by these above factors as illustrated in Figure 5. Sauropsid embryos possess a large eyeball in relation to the body. In chick embryos, the ophthalmic nerve anlage is situated dorsal to the eyeball and thus near the ectoderm; however, by stage 20 , because of the rapid increase in the eyeball diameter, the middle portion of the ophthalmic nerve comes to lie medial to the eyeball and consequently, the nerve detaches from the ectoderm (KURATANI and TANAKA, 1990). The 
pontine flexure also plays a role in the ventromedial movement of the ophthalmic ganglion. According to D'AMICO-MARTEL (1982), the placode-derived neurons are generated between 2 to 5 days of incubation. For the latter half of this period, the ophthalmic ganglion is situated far medially from the ectoderm. It seems most appropriate to assume that the ectopic ganglion, or the vestigial ophthalmic placode cells, failed to be freed from the ectoderm after most of the placodal contribution had ceased and the ophthalmic ganglion had shifted ventromedially far medial to the eyeball. The ectopic ganglion, then, is a manifestation of an incident in the developmental design of the cranial nerve ganglia.

As for the fate of the above described ectopic ganglia, no information was obtained in the present study. Nichols (1986) observed the apical domes/ blebs in the trigeminal placode and assumed that they might be pinched off into the amniotic cavity. This would also hold true for the ectopic ganglia. Such would explain their absence in the embryo after stage 27 in the chick embryo.

Acknowledgments. We thank Dr. G. CIMENT for the E/C8 antibody, Dr. D. A. Welter for his technical advice in SEM, Ms. B. K. HEADUCK for her technical assistance in TEM, and Dr. Theresa HARRISON for her critique of the manuscript.

\section{REFERENCES}

Bartelmez, G. W. and H. M. Evans: Development of the human embryo during the period of somite formation, including embryos with 2 to 16 pairs of somites. Contrib. Embryol. 17: 1-67 (1926).

BAtTen, E. H.: The activity of the trigeminal placode in the sheep embryo. J. Anat. 91: 174-187 (1957).

Ciment, G., A. Ressler, P. C. Letourneau and J. A. WESTON: A novel intermediate filement-associated protein, NAPA-73, that binds to different filament types at different stages of nervous system development. J. Cell Biol. 102: 246-251 (1986).

Coers, C.: La formation des nerfs mixtes craniens chez le lapin. Arch. Biol. Paris 57: 13-79 (1946).

Coghill, G. E.: Correlated anatomical and physiological studies of the growth of the nervous system of amphibia. J. Comp. Neurol. 26: 247-340 (1916).
D'Amico-MaRTel, A.: Temporal patterns of neurogenesis in avian cranial sensory and autonomic ganglia. Amer. J. Anat. 163: 351-372 (1982).

D'Amico-M ARTel, A. and D. M. Noden: Contributions of placodal and neural crest cells to avian cranial peripheral ganglia. Amer. J. Anat. 166: 445-468 (1983).

GoLDBY, F.: On the presence of a series of ectodermal placodes in the head region of a sparrow embryo. Amer. J. Anat. 62: 135-138 (1928).

HALLEY, G.: The placodal relation of the neural crest in the domestic cat. J. Anat. 89: 133-152 (1955).

Hamburger, V. and H. Hamilton: A series of normal stages in the development of the chick embryo. J. Morphol. 88: 49-67 (1951).

Ishikawa, Y., C. Zukeran, S. Kuratani and S. Tanaka: A staining procedure for nerve fibers in whole mount preparations of the medaka and chick embryos. Acta Histochem. Cytochem. 19: 775-783 (1986).

Johnston, M. C. and R. D. Hazelton: Embryonic origins of facial structures related to oral sensory and motor function. In: (ed. by) J. B. Bosma: Third Symposium on Oral sensation and perception: The mouth of the infant. Chas. C. Thomas, Springfield, IL, 1972 (p. 7697).

Kuratani, S. and S. Tanaka: Peripheral development of the avian trigeminal nerves. Amer. J. Anat. 187: 65-80 (1990).

Le Douarin, N. M., M. A. Teillet and J. FontainePerus: Chimeras in the study of the peripheral nervous system of birds. In: (ed. by) N. M. LE DOUARIN and A. MCLAREN: Chimeras in developmental biology. Academic Press, London, 1984 (p. 313-352).

Newth, D. R.: On the neural crest of the lamprey embryo. J. Embryol. Exp. Morphol. 4: 358-375 (1956).

Nichols, D. H.: Mesenchyme formation from the trigeminal placodes of the mouse embryo. Amer. J. Anat. 176: 19-31 (1986).

YNTEMA, C. L.: Experiments on the origin of the sensory ganglia of the facial nerve in the chick. J. Comp. Neurol. 81: 147-167 (1944). 